\title{
Ion-Neutral Complexes Resulting from Dissociative Protonation: Fragmentation of $\alpha$-Furanylmethyl Benzyl Ethers and 4-N,N-dimethylbenzyl Benzyl Ethers
}

\author{
Pengyuan Liu, ${ }^{\mathrm{a}}$ Nan $\mathrm{Hu},{ }^{\mathrm{a}}$ Yuanjiang Pan, ${ }^{\mathrm{a}}$ and Yaping $\mathrm{Tu}^{\mathrm{b}}$ \\ a Department of Chemistry, Zhejiang University, Hangzhou, Zhejiang, China \\ b Drug Metabolism and Pharmacokinetics, Infectious Diseases Center of Excellence for Drug Discovery, \\ GlaxoSmithKline, Research Triangle Park, North Carolina, USA
}

The loss of $\mathrm{CH}_{2} \mathrm{O}$ during mass spectrometry in two series of $\alpha$-aromaticmethyl benzyl ether compounds, namely, $\alpha$-furanylmethyl $p$-substituted-benzyl ethers and 4- $N, N$-dimethylbenzyl $p$-substituted-benzyl ethers, is particularly interesting. The fragmentation mechanism is proposed to involve an ion-neutral complex-mediated pathway. Specifically, before the formation of an ion-neutral intermediate, the proton is transferred from the thermodynamically favored site at either the ether oxygen atom or the nitrogen atom to the dissociative protonation site at $C_{\alpha}$ position in either the furyl group or the 4- $N, N$-dimethylphenyl group. This transfer has been clarified via computational studies and isotopically labeled experiments. In addition, the decomposition of the intermediate may be affected by the substituent groups on the phenyl ring. This conclusion is indicated by the reasonably good correlation between $\ln \left[\left(\left[\mathrm{M}+\mathrm{H}-\mathrm{CH}_{2} \mathrm{O}\right]^{+}\right) /\left(\left[\mathrm{M}+\mathrm{H}-\mathrm{CH}_{2} \mathrm{O}-\mathrm{C}_{6} \mathrm{H}_{5} \mathrm{R}\right]^{+}\right)\right]$and the substituent constants. (J Am Soc Mass Spectrom 2010, 21, 626-634) @ 2010 American Society for Mass Spectrometry

$\mathrm{I}$ t has been nearly three decades since the definition of ion-neutral complexes was introduced [1-3]. Even before that time, approximately half a century ago, the concept of ion-neutral complexes was first proposed to explain the loss of identity in labeled benzyl produced from tert-butylbenzene [4]. Since then, mechanisms involving the complexes of "weakly coordinated cations" have been suggested to explain a number of otherwise puzzling reactions of ions in the gas-phase [3, 5-9]. Specifically, when an ion encounters a neutral molecule in the gas phase, the interaction may lead to the formation of a loose complex in which the ion and neutral molecule are held together by electrostatic forces, but still maintain their individual mobility [8]. These ion-neutral complexes may decompose into a product ion and a neutral species, may fragment and recombine into covalently bonded molecular ions, or may undergo another ion-molecule reaction for which the stabilization energy of the products is small. In short, ion-neutral complex-mediated unimolecular decomposition processes involve either a direct cleavage without a significant barrier or further internal ionmolecule reactions.

Ion-neutral complexes have been found to be ubiquitous in gas-phase ionic reactions. However, most

Address reprint requests to Professor Y. Pan, Department of Chemistry, Zhejiang University, Hangzhou, Zhejiang 310027, China. E-mail: panyuanjian@ zju.edu.cn and yaping.5.tu@gsk.com early investigations into the subject focused on theoretical studies of postulated reactions pathways involving ion-neutral complex intermediates and the corresponding transition structures [10-12] because experimentally verifying that ion-neutral complexes were intermediates in gas-phase ionic reactions and characterizing those intermediates in detail were not simple tasks. Several classical experimental methods, such as isotopic labeling experiments $[4,13,14]$, kinetic isotope effects [15-17], and kinetic methods [18-20] can provide indirect evidence to support a proposed ionneutral complex-mediated mechanism. Among these methods, the classical method of studying the substituent influence has proved useful in the analysis of mechanisms that involve ion-neutral complex intermediates [16, 21], whose dissociation pathways can be affected by the electronic effects exerted by substituents that influence the kinetic energy of the ion-neutral complex. In particular, there is an obvious correlation between substituent effects and the relative abundance of product ions in mass spectrometry experiments.

Recently, a pathway involving an ion-neutral complex intermediate has been proposed by one of us to explain the loss of a $\mathrm{CH}_{2} \mathrm{O}$ molecule from protonated dibenzyl ether under collision-induced dissociation (CID) conditions [19]. This dissociation is completely different from the rearrangement process involving the difficult formation of a $\mathrm{C}_{\beta}-\mathrm{C}_{\beta}$ bond between two phenyl rings that was reported earlier by Kingston et al. 
[22]. To gain insight into this interesting loss of $\mathrm{CH}_{2} \mathrm{O}$ from the dibenzyl ether compounds and to clarify the ion-neutral complex-mediated mechanism, two series of compounds, an $\alpha$-furanylmethyl benzyl ether along with several $p$-substituted phenyl derivatives, and a $4-N, N$-dimethylbenzyl benzyl ether along with several $p$-substituted phenyl derivatives were synthesized and investigated by mass spectrometry. These two series of compounds are representative either of $\alpha$-arometicmethyl benzyl ethers in general or of dibenzyl ether in particular. Under CID conditions, the protonated molecular ions of these ethers also gave mass spectra that indicated the loss of $\mathrm{CH}_{2} \mathrm{O}$, in a manner similar to that of dibenzyl ether. In addition, the relative abundance of the corresponding product ions have been found to clearly depend on their substituent constants, which is clear evidence of an ion-neutral complex-mediated mechanism, because the dissociation pathway leading to the product ions can be significantly influenced by the substituents on the substrate in ion-neutral complex-mediated mechanisms.

\section{Experimental}

The substituted $\alpha$-furanylmethyl benzyl ethers and $4-N, N$-dimethylbenzyl benzyl ethers were prepared through a modification of the Williamson ether synthesis. The structures of the products were verified by independent synthesis, ${ }^{1} \mathrm{H}$ NMR, ${ }^{13} \mathrm{C}$ NMR, and highresolution mass spectrometry after their purification.

The samples were first analyzed on a Bruker Esquire 3000 plus mass spectrometer (Bruker, Billerica, MA, USA) equipped with an ESI ion source in positive ionization mode. All the data were acquired using the Esquire 5.0 software. The compounds were first dissolved in a methanol and $1 \%$ acetic acid in water (3:1) solution. The solutions were infused into the source chamber at a flow rate of $3 \mu \mathrm{L} \mathrm{min}{ }^{-1}$ while nitrogen was used as the nebulizing gas at a pressure of $15 \mathrm{psi}$, and the drying gas was set at a flow rate of $5 \mathrm{~L} \mathrm{~min}^{-1}$. The capillary voltage was set at $4000 \mathrm{~V}$, and the ion source temperature was $250{ }^{\circ} \mathrm{C}$. The collision-induced dissociation (CID) mass spectra were obtained using helium as the collision gas. After the isolation of the precursor ions, the collision energy was set to give suitable energy for the dissociation of all samples.

Accurate masses were measured on an ApexIII (7.0 tesla) FTICR mass spectrometer (Bruker). Sodium iodide was selected as the external calibration compound for positive ion electrospray ionization mass spectrometry in the mass range from 100 to $1200 \mathrm{Da}$. The solutions were infused from the ESI source at $3 \mu \mathrm{L} \mathrm{min}{ }^{-1}$ using the following parameters: capillary, $-4200 \mathrm{~V}$; end plate, $3767 \mathrm{~V}$; skimmer 1, $13.23 \mathrm{~V}$; skimmer 2, $6.5 \mathrm{~V}$; offset, $1.03 \mathrm{~V}$; rf amplitude, $500 \mathrm{~Hz}$; drying gas temperature, $150{ }^{\circ} \mathrm{C}$. Nitrogen was used as both the nebulizing gas and the drying gas, while argon was used as the collision gas. MS/MS parameters were as follows: correlation sweep pulse length, $2000 \mu$ s; correlation sweep attenuation, $19.5 \mathrm{~dB}$; ejection safety belt, $100 \mathrm{~Hz}$; user pulse delay length, $0.005 \mathrm{~s}$; and user delay length, $3 \mathrm{~s}$.

Calculations were performed by using DFT methods at the RB3LYP/6-31G(d) level of theory using Gaussian 03. Candidate structures for the reactants and products were optimized by calculating force constants. No symmetry constrains were imposed in the optimizations. All optimized structures were subjected to vibrational frequency analysis to allow for zero-point energy (ZPE) correction to $298.15 \mathrm{~K}$ and $1.0 \mathrm{~atm}$ of pressure. The sum of the electronic and thermal energies for the optimized structures was calculated.

\section{Results and Discussion}

The compounds selected in this study were expected to have the particular fragmentation loss of $\mathrm{CH}_{2} \mathrm{O}$, which occurs when a proton migrates from the thermodynamically favored site to the key dissociative protonation site $[19,23,24]$. The compounds tested were selected to be representative of different kinds of molecules, including (1) $\alpha$-aromatic heterocycle methyl benzyl ethers, and (2) substituted-benzyl benzyl ethers. Specifically, the compounds in the two groups were $\alpha$-furanylmethyl benzyl ethers and 4-N,N-dimethylbenzyl benzyl ethers, respectively. Investigating these two groups of representative compounds, not only allows the systematic study of these compounds' fragmentation mechanism, but also allows for extensive investigation of these $\alpha$-arometicmethyl benzyl ethers' particular loss habit.

\section{$\alpha$-Aromatic Heterocycle Methyl Benzyl Ether}

The furan in these compounds is representative of aromatic heterocycles in general. The molecular structures of $\alpha$-Furanylmethyl benzyl ether (Compound 1) and its derivatives (Compounds 2-8) are shown in Table 1. Protonated molecular ions of all the compounds were produced under positive ion ESI conditions. Mass spectra from MS/MS experiments were obtained under the conditions described in the experimental section. Generally, Compounds 1-8 produced

Table 1. Structures of Compounds 1-8

\begin{tabular}{cll}
\hline Compounds & $\mathrm{MW}$ & \\
\hline \hline 1 & 188 & $\mathrm{R}$ \\
2 & 231 & $\mathrm{H}$ \\
3 & 218 & $\mathrm{~N}\left(\mathrm{CH}_{3}\right)_{2}$ \\
4 & 202 & $\mathrm{OCH}$ \\
5 & 206 & $\mathrm{CH}$ \\
6 & 222 & $\mathrm{Fl}$ \\
7 & 266 & $\mathrm{Cr}_{3}$ \\
8 & 230 & $\mathrm{COCH}_{3}$ \\
\hline
\end{tabular}


similar fragment ions in the positive ESI-MS/MS experiments. The only effect of the substituents on the reaction was to alter the relative abundances of the fragment ions.

There were several different types of fragmentation reactions generated by the compounds, but the major fragmentations were produced by cleavage of the ether and loss of formaldehyde. As a general rule, the major fragmentations are expected to be produced directly from the $\mathrm{MH}^{+}$ions in which the proton is attached at the thermodynamically favored site. Hence, the protonation site of all compounds in the study was determined at the outset of this work.

$\alpha$-Furanylmethyl benzyl ether can be considered an analog of dibenzyl ether. Early studies showed that in dibenzyl ether, as well as in its derivatives, the oxygen atom was the thermodynamically favored site of protonation [19]. This result is in agreement with the fact that the proton affinity (PA) values of ethers $(\sim 810 \mathrm{~kJ} / \mathrm{mol})$ are usually higher than those of benzenes $(\sim 750 \mathrm{~kJ} /$ mol) [25]. However, in the case of $\alpha$-furanylmethyl benzyl ether and its derivatives, the furyl group is another possible site of protonation because the PA value for furan $(803.4 \mathrm{~kJ} / \mathrm{mol})$ is similar to that of ether ( $\sim 810 \mathrm{~kJ} / \mathrm{mol})$ [25]. In addition, computations using Gaussian $03 \mathrm{~W}$ were conducted to identify the protonation sites. For the sake of simplicity, Compound 1, $\alpha$-furanylmethyl benzyl ether, was selected as an example in this paper. Specifically, the structures containing different protonated sites, such as the ether, phenyl, and furyl groups, were optimized using Gaussian 03W at the B3LYP/6-31G(d) level. The total energy of these structures is summarized in the Supporting Information, which can be found in the electronic version of this article. Additionally, it has been reported that the $C_{\alpha}$ is the thermodynamically favored site of protonation relative to the $\mathrm{C}_{\beta}$ and $\mathrm{O}$ atom in the furan molecule [26], which indicates that the proton should be attached to the $\mathrm{C}_{\alpha}$ site in the case of a $\mathrm{MH}^{+}$ion protonated at furyl. Overall, the computation results in this study indicated that the oxygen atom was the protonation site because that molecular ion had the lowest energy.
As an example of the characteristic fragmentations observed for the compounds studied here, the ESIMS/MS spectrum of protonated Compound 1 is shown in Figure 1a. Upon collisional activation, the protonated molecular ion at $\mathrm{m} / \mathrm{z} 189$ yielded three major product ions at $m / z 159,91$ and 81, respectively. Several other common fragmentations were also observed, such as the ion at $m / z 171$ that results from the loss of $\mathrm{H}_{2} \mathrm{O}$, and the ion at $m / z 145$ that results from the loss of $\mathrm{C}_{2} \mathrm{H}_{4} \mathrm{O}$ in the furyl group. For clarity, the following discussion about the fragmentation mechanism will be focus on the three major products. In general, the ion at $m / z 91$ is the benzyl cation and the ion at $m / z 81$ is the furylmethyl cation. However, the loss of $30 \mathrm{Da}$ in molecular mass, which has been confirmed by FTICR-MS/MS to result from the loss of $\mathrm{CH}_{2} \mathrm{O}$, cannot be rationalized without invoking skeletal rearrangements before the fragmentation. In this study, we propose a similar ion-neutral complex intermediate involved mechanism that is based on the mechanism of $\mathrm{CH}_{2} \mathrm{O}$ loss from dibenzyl ether [19]. In the mechanism, the proton is transferred from $\mathrm{O}$ to $\mathrm{C}$ on the skeleton via a 1,3-H shift, and then an ion-neutral complex intermediate is formed as the result of $\mathrm{C}-\mathrm{C}$ bond elongation. The product ions at $m / z 159$ are generated via the loss of $\mathrm{CH}_{2} \mathrm{O}$ from the ion-neutral complex intermediate. However, unlike the dibenzyl ether case, when considering the $\alpha$-furanylmethyl benzyl ether there are two different possible ion-neutral intermediates that may be formed. The formation of the intermediates depends on the direction of the proton transfer. Specifically, if the proton transfers to phenyl, an intermediate consisting of a 2-furanylmethoxy-methyl cation and a neutral phenyl complex will be formed, and the proton will be attached to the phenyl group when the product ion is formed via loss of $\mathrm{CH}_{2} \mathrm{O}$. In contrast, if the proton transfers to furyl, the other possible intermediate, a complex of benzyloxymethyl cation and a neutral furan will be formed, and the proton will be attached to the furyl group when the product ion is formed via loss of $\mathrm{CH}_{2} \mathrm{O}$.

Due to the important role it plays in the reaction, the proton transfer direction should be discussed before the fragmentation mechanism. Calculations of $\mathrm{MH}^{+}$ions

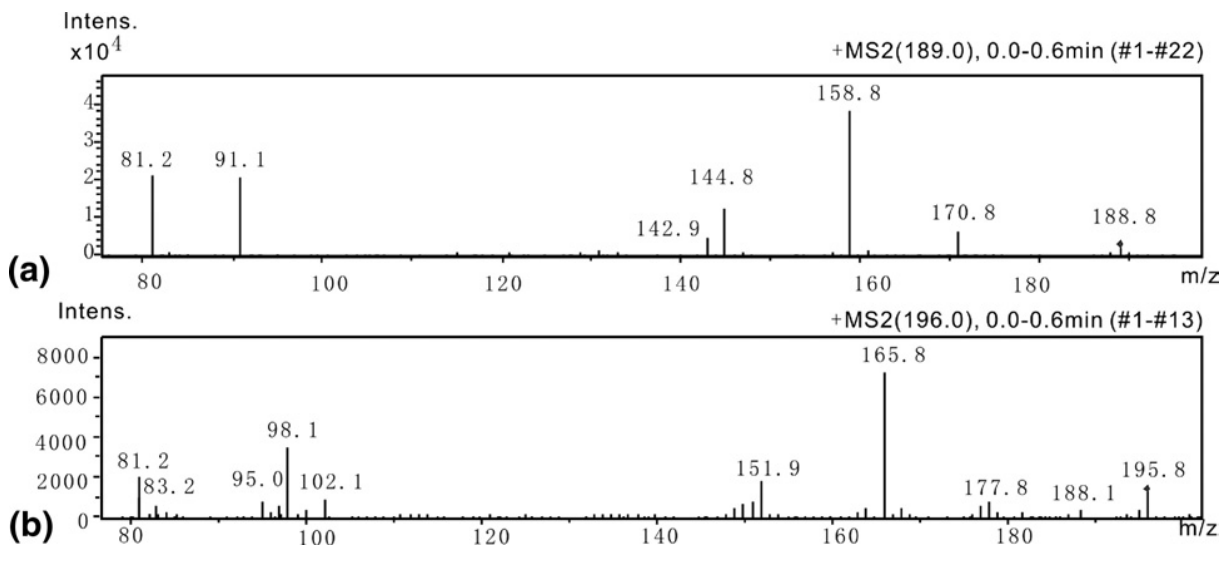

Figure 1. The CID spectrum of protonated (a) Compound 1 and (b) Compound 9. 
can be utilized to determine the protonation site and the pathways of proton transfer. In particular, it has been found via Gaussian 03W using the B3LYP/6-31G(d) level of theory that the total energy of the $\mathrm{MH}^{+}$ion protonated at the furyl $\mathrm{C}_{\alpha}$ was much lower than that of the $\mathrm{MH}^{+}$ion protonated at the phenyl $\mathrm{C}_{\alpha}$ (Please see the Supporting Information for details). This calculation suggests that the proton is more likely to transfer to the furyl group than the phenyl group.

To verify the conclusions drawn from the calculations, Compound 9, benzyl- $\mathrm{d}_{7}, 2$-furanmethyl ether (Figure 2), was synthesized to check the direction of proton transfer. The fragmentation ions resulting from $\mathrm{MH}^{+}$in Compounds 1 and 9 are almost the same (Figure 1). However, the two possible directions of proton transfer in Compound 9 will generate two different product ions with different $m / z$ values. Specifically, if the proton transfers to the furyl group, the loss of $\mathrm{CH}_{2} \mathrm{O}$ from the intermediate will generate a product ion at $m / z 166$. On the contrary, if the proton transfers to the phenyl- $\mathrm{d}_{5}$ group, a loss of $\mathrm{CD}_{2} \mathrm{O}$ would be expected to give the product ion at $\mathrm{m} / \mathrm{z} 164$. Consequently, the two possible pathways can be readily distinguished from one another. According to the ESI-MS/MS spectrum of protonated Compound 9, which is shown in Figure $1 \mathrm{~b}$, the fragment at $m / z 166$ is observed as the base peak but no fragment ion at $m / z 164$ is detected. Therefore, the results from the isotopically labeled compound are consistent with the result of the relative energy calculations, which suggest the proton should be transferred to the furyl group rather than the phenyl group.

In addition, it was found that in the case of substituted $\alpha$-furanylmethyl benzyl ethers, the substituents do affect the stability of the $\mathrm{MH}^{+}$ions. Because electron-donating substituents on the phenyl ring can stabilize proton transfer from the initial protonation site to the phenyl group, compounds carrying a strong electron-donating substituent have been a focus of computational studies. Thus, the energies of the different protonated $\mathrm{MH}^{+}$structures for Compound 3, which carries a para-methoxy substituent, have been optimized at the B3LYP/6-31G(d) level. The total energies for these structures are given in the supporting material. Compared with the $\mathrm{MH}^{+}$ions of Compound 1 , the difference in the total energy between the $\mathrm{MH}^{+}$ structure protonated at the phenyl group and the $\mathrm{MH}^{+}$structure protonated at the furyl group of Compound 3 is significantly decreased. However, the results indicate that the $\mathrm{MH}^{+}$structure protonated at the furyl group is still more energetically favorable,

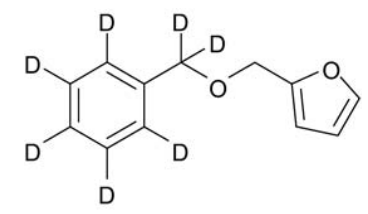

Figure 2. The structure of Compound 9.

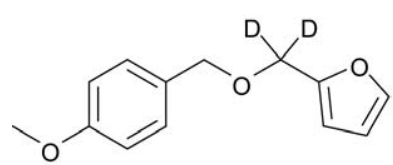

Figure 3. The structure of Compound 10.

even though the energy difference between the two protonated structures has decreased. Furthermore, the direction of proton transfer has been proved using the isotopically labeled substrate. Compound 10 (Figure 3), 4-methoxybenzyl, 2-furanmethyl- $\mathrm{d}_{2}$ ether, was synthesized to check the proton transfer direction. As with the fragmentation of protonated Compound 9, the two possible proton transfer pathways can be completely distinguished from one another. According to the ESI-MS/MS spectrum of protonated Compound 10 (see the Supporting Information), a fragment at $\mathrm{m} / \mathrm{z} 189$ (loss of $\mathrm{CD}_{2} \mathrm{O}$ ) is evident but no fragment ion at $\mathrm{m} / \mathrm{z} 191$ (loss of $\mathrm{CH}_{2} \mathrm{O}$ ) is observed. These experimental MS/MS results are consistent with the computational results, which suggest that the proton should be transferred to the furyl group.

In contrast, the computational results regarding the possible $\mathrm{MH}^{+}$structures of Compound 2, which have a $\mathrm{NMe}_{2}$ substituent, reveal that the total energy of the structure resulting from proton transfer to the phenyl group is $71 \mathrm{~kJ} / \mathrm{mol}$ lower than the structure resulting from proton transfer to the furyl group, which indicates that the proton will transfer to the phenyl group in $\mathrm{MH}^{+}$structures of Compound 2. In summary, an electron-donating substituent on the phenyl group can increase the stability of the phenyl group protonated $\mathrm{MH}^{+}$structure, however, only the $\mathrm{NMe}_{2}$ group, the strongest electron-donating group in our study, is strong enough to alter the direction of proton transfer.

Based on the above results and discussion, Scheme $\mathbf{1}$ can be proposed. A simplified fragmentation mechanism for $\alpha$-furanylmethyl benzyl ether and its derivatives (except for Compound 2) is shown in Scheme $\mathbf{1}$. Specifically, in positive ESI-MS/MS mode, the $\mathrm{MH}^{+}$ ion, a-1, is produced by protonation of the ether bond. Then, the product ions a- 4 and a- 5 are directly produced by the cleavage of the ether bond. Alternatively, the other form of $\mathrm{MH}^{+}$ion, a-2, can also be produced by transferring the proton to the $\mathrm{C}_{\alpha}$ in the furyl group, which can decompose to the ion-neutral complex intermediate a-3 that consists of a benzyloxy-methyl cation and a neutral furan, and that is formed by the elongation of the $\mathrm{C}-\mathrm{C}$ bond before fragmentation. Product ion a- 6 results from the loss of $\mathrm{CH}_{2} \mathrm{O}$ from Complex a-3. The relative abundances (RA) of the major product ions for all the compounds in this study are summarized in Supporting Material. Moreover, the loss of $\mathrm{CH}_{2} \mathrm{O}$ could still be observed in the CID spectrum of Compound 2, which indicates that the $\mathrm{NMe}_{2}$ substituent only influences the direction of proton transfer, but does little to the ion-neutral intermediate involved mechanism after dissociative protonation. 


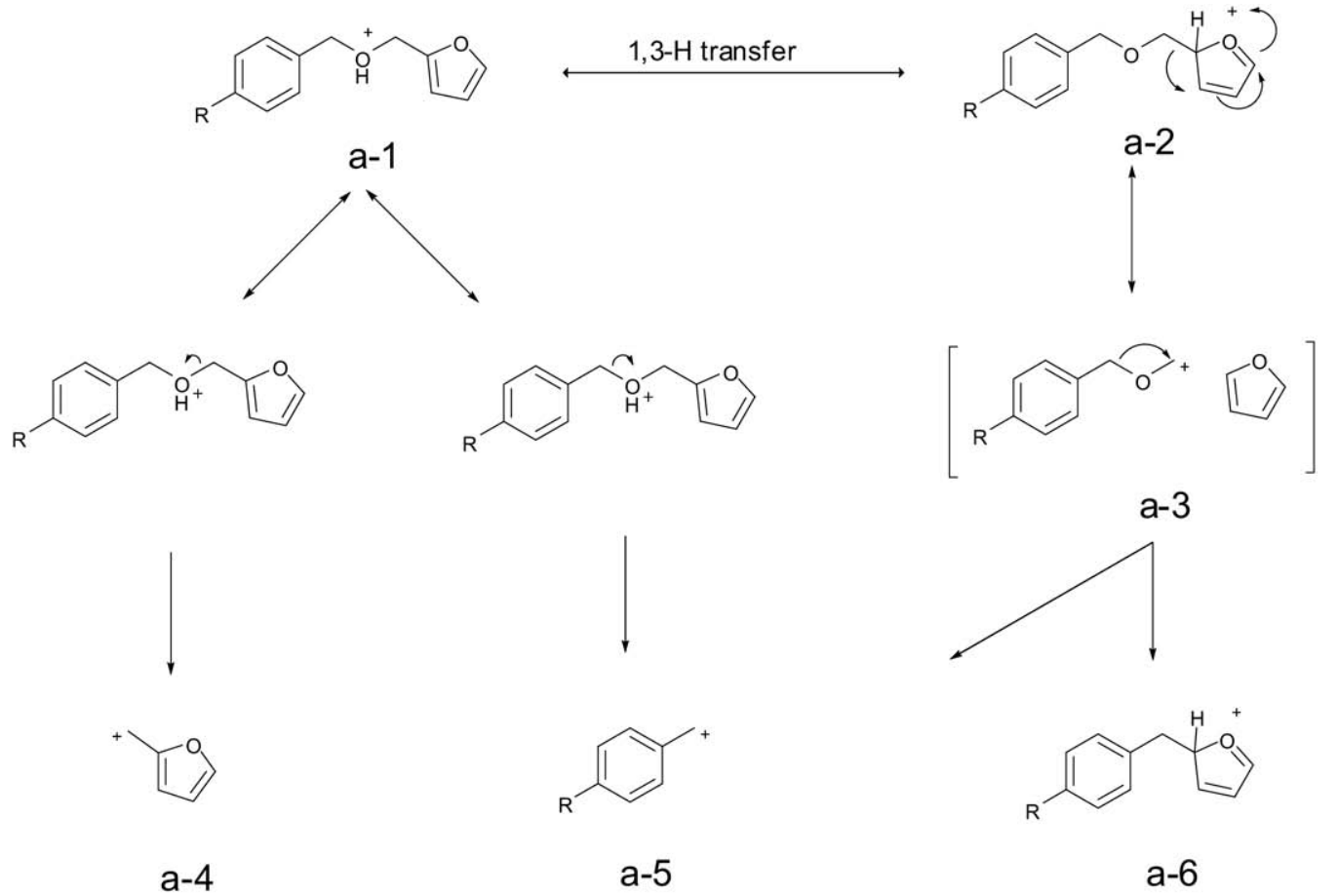

Scheme 1. Proposed MS/MS fragmentation mechanism of protonated $\alpha$-furanylmethyl benzyl ether and its derivatives.

Furthermore, we have noticed that the collisional energy influences the relative intensity of fragment ions. In the case of Compound 1, as the collision energy increases, the relative intensity of the $m / z 159$ ion ([M + $\left.\mathrm{H}-\mathrm{CH}_{2} \mathrm{O}\right]^{+}$) decreases, while that of the $m / z 91$ ion $\left(\left[\mathrm{M}+\mathrm{H}-\mathrm{CH}_{2} \mathrm{O}-\mathrm{C}_{4} \mathrm{H}_{4} \mathrm{O}\right]^{+}\right)$increases (Figure 4). This is consistent with the fact that the intermediate, ionneutral Complex a-3 collapses more readily when the collision energy is higher and thus the reaction via the complex becomes less competitive.

It was also determined that the substituent only affected the relative abundances of the fragment ions. As shown in Scheme 1, the ion-neutral complex intermediate a- 3 can generate two product ions, a- 5 and a- 6 . The amount of these two competitive product ions can be significantly affected by substituents on the phenyl ring, which alter the stability of the product ions. Specifically, an electron-donating substituent connected to the phenyl ring can increase the electronegativity of the phenyl ring, thereby stabilizing product ions of type

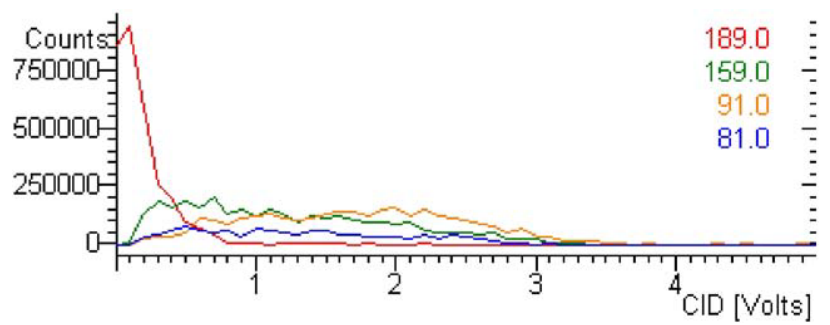

Figure 4. Dependence of the parent ion and the product ion intensities on collision energy in CID reactions of Compound 1. a-5. In contrast, an electron-withdrawing substituent can increase the phenyl ring electropositivity, thereby destabilizing product ions of type a-5. In other words, the formation of product ion a- 6 can be either expedited by an electron-withdrawing substituent or impeded by an electron-donating substituent.

To systematically study the effects of substituents on the ion-neutral complex intermediates, the mass spectra of a series of compounds containing different substituents at the para position of the phenyl ring were

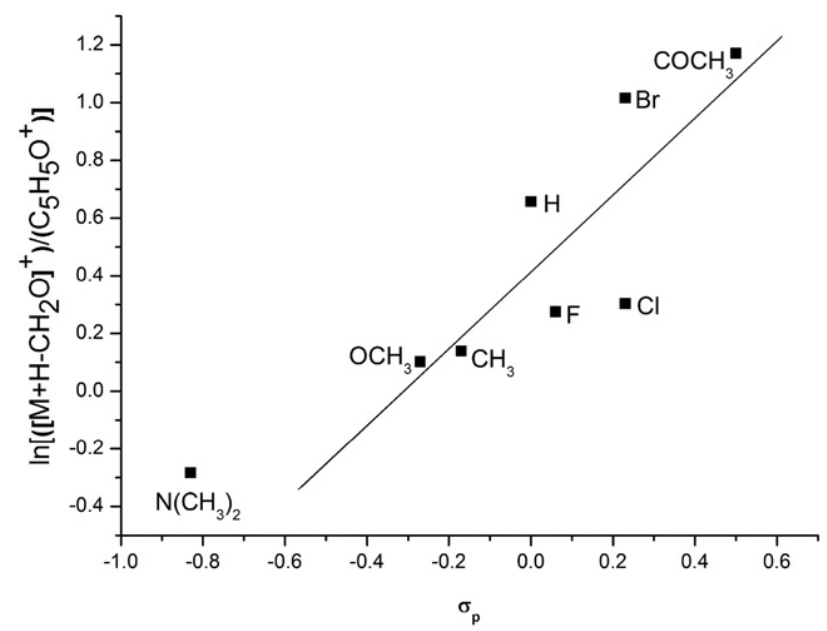

Figure 5. Plot of $\ln \left[\left(\left[\mathrm{M}+\mathrm{H}-\mathrm{CH}_{2} \mathrm{O}\right]^{+}\right) /\left(\mathrm{C}_{5} \mathrm{H}_{5} \mathrm{O}^{+}\right)\right]$versus the $\sigma_{\mathrm{p}}$ substituent constants for the collision-induced fragmentation of $\mathrm{MH}^{+}$ions of $\alpha$-furanylmethyl benzyl ethers substituted at the para position. Collision energy is $0.60 \mathrm{~V}$ (helium). 
Table 2. Structures of Compounds 11-19

\begin{tabular}{|c|c|c|}
\hline Compounds & MW & $\mathrm{R}$ \\
\hline 11 & 241 & $\mathrm{H}$ \\
\hline 12 & 286 & $\mathrm{NO}_{2}$ \\
\hline 13 & 284 & $\mathrm{~N}\left(\mathrm{CH}_{3}\right)_{2}$ \\
\hline 14 & 255 & $\mathrm{CH}_{3}$ \\
\hline 15 & 271 & $\mathrm{OCH}_{3}$ \\
\hline 16 & 309 & $\mathrm{CF}_{3}$ \\
\hline 17 & 259 & $\mathrm{~F}$ \\
\hline 18 & 275 & $\mathrm{Cl}$ \\
\hline 19 & 319 & $\mathrm{Br}$ \\
\hline
\end{tabular}

measured (the relative abundance of the product ions are provided in the Supporting Information). Two major product ions, a- 6 and a-4, were chosen to examine the substituent effects and the intensity ratios of these two ions. The plot of $\ln \left[\left(\left[\mathrm{M}+\mathrm{H}-\mathrm{CH}_{2} \mathrm{O}\right]^{+}\right) /\right.$ $\left.\left.\left(\mathrm{C}_{5} \mathrm{H}_{5} \mathrm{O}^{+}\right)\right]\right)$versus the substituent constants, $\sigma_{\mathrm{p}}$ is shown in Figure 5. Here the substituent constant, $\sigma_{\mathrm{p}}$ [27] was used because the formation of fragment ions $\left[\mathrm{M}+\mathrm{H}-\mathrm{CH}_{2} \mathrm{O}\right]^{+}$could be influenced by $p$-position substituents as discussed above. The product ion a-5 was not used in this analysis because it can be produced via two different pathways (Scheme 1), which complicates the discussion. In contrast, the formation of the product ion a-4 is straightforward in the simplified fragmentation mechanism (Scheme 1), and can hardly be affected by the substituents present. Consequently, the substituent's influence will only felt in generation of product ion a-6 compared with a-4. Specifically, as shown in Figure 5, electron-withdrawing or electrondonating groups can expedite or slow down the formation of product ion a-6, respectively. This finding is consistent with the proposed mechanism in Scheme 1, and strongly supports an ion-neutral complex intermediate-involved mechanism. Furthermore, Compound 2 does not fit this trend because the $\mathrm{NMe}_{2}$ substituent can change the direction of proton transfer, which results in a different fragmentation mechanism.

\section{Substituted-Benzyl Benzyl Ethers}

4-N,N-dimethylbenzyl benzyl ether, as a derivative of dibenzyl ether, was selected to be representative of substituted-benzyl, benzyl ethers in general. Additionally, 4- $N, N$-dimethylbenzyl benzyl ether and its $p$-substituted phenyl derivatives were synthesized and investigated using the same methods applied to the $\alpha$-furanylmethyl benzyl ethers. The structures of the series of compounds (Compounds 11-19) are shown in Table 2. For all the compounds, the protonated molecular ions were produced under positive ion ESI conditions. In the MS/MS experiments, the mass spectra were obtained under the same conditions described in the experimental section. Almost all the compounds in this series showed fragmentations similar to those seen in the first series, and again the substituent at 4-position of the phenyl group only affected the relative abundance of common fragment ions.

An initial problem in this study was the protonation site for this series of compounds. In the case of $4-\mathrm{N}, \mathrm{N}-$ dimethylbenzyl benzyl ether, the PA value of the $\mathrm{p}$ $\mathrm{N}\left(\mathrm{CH}_{3}\right)_{2}$ substituted phenyl $(941.1 \mathrm{~kJ} / \mathrm{mol})$ is higher than that of the ether $(\sim 810 \mathrm{~kJ} / \mathrm{mol})$ [25]. Of course, the nitrogen atom is another possible thermodynamically favored site of protonation in addition to the oxygen atom. This issue was also studied by computation using Gaussian 03W. The results show that the total energy of the equilibrium structure of the $\mathrm{MH}^{+}$ion protonated at nitrogen is $28 \mathrm{~kJ} / \mathrm{mol}$ lower than that of the $\mathrm{MH}^{+}$ion protonated at oxygen. Therefore, the initial protonation site for this series of compounds is probably the nitrogen atom. However, almost no direct fragmentation was obtained from this nitrogen protonated structure. The main fragmentation reaction, including the cleavage of the ether bond and the loss of $\mathrm{CH}_{2} \mathrm{O}$, must be triggered by a proton migration from the initial site of protonation to other dissociative protonation sites. Thus, proton transfer before fragmentation is proposed. Although the proton transfer over the phenyl ring

(a)
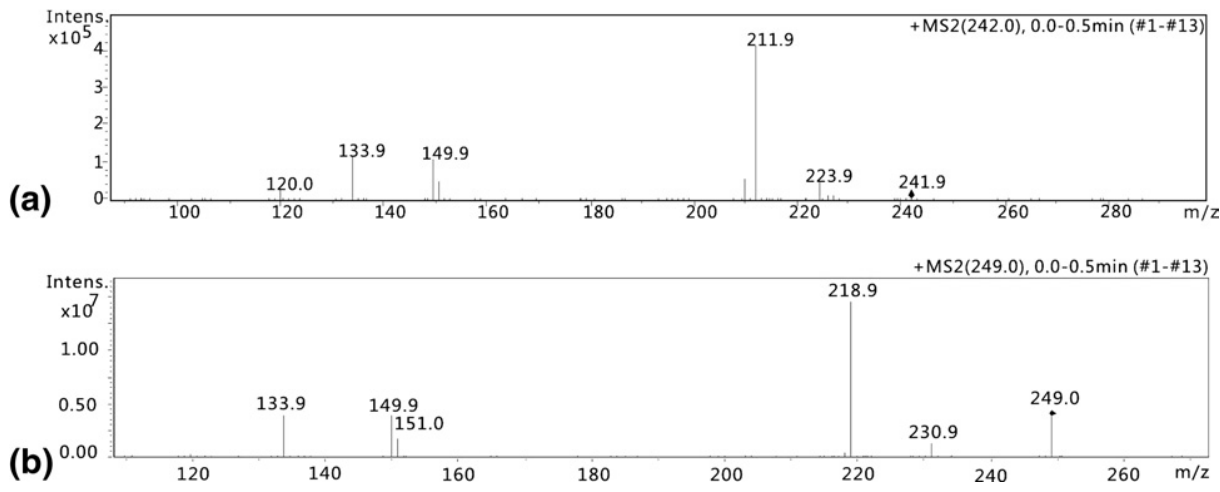

Figure 6. The CID spectrum of protonated (a) Compound 11 and (b) Compound 20. 


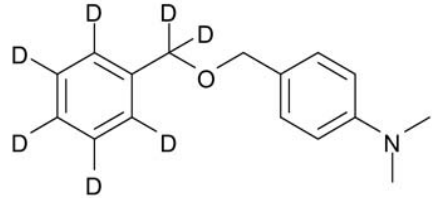

Figure 7. The structure of Compound 20.

seems difficult, it could take place by ring walk [28]. As with the series of $\alpha$-furanylmethyl benzyl ethers, the oxygen and the phenyl $\alpha$-carbons are the probable dissociative protonation sites.

In view of the proton transfer and fragmentation mechanism described for the $\alpha$-furanylmethyl benzyl ethers, we shall attempt to explain the dissociation pathways. In the CID mass spectrum of protonated Compound 11 (Figure 6a), the main fragmentation, aside from some other product ions at $m / z 224,150,151$, and 120 , is the loss of $\mathrm{CH}_{2} \mathrm{O}$ and the cleavage of the ether bond, which could not form without the proton attached to the nitrogen. As with the series of $\alpha$-furanylmethyl benzyl ethers, the phenyl $\mathrm{C}_{\alpha} \mathrm{s}$ and the oxygen atom could be the dissociative protonation sites to which the proton transfers from nitrogen, the initial protonation site. The ether bond cleavage would then happen after the proton transfer to the oxygen atom. Proton transfer to $\mathrm{C}_{\alpha}$ in the $p-\mathrm{N}\left(\mathrm{CH}_{3}\right)_{2}$ substituted phenyl leads to a benzyloxy-methyl cation and a neutral $p$ - $\mathrm{N}\left(\mathrm{CH}_{3}\right)_{2}$ substituted phenyl complex intermediate, which in turn results in the loss of $\mathrm{CH}_{2} \mathrm{O}$.

The direction of proton transfer was also studied by investigating isotope-labeled 4-N,N-dimethylbenzyl benzyl ether, Compound 20 (Figure 7), because the different proton transfer directions will form different ion-neutral complex intermediates, as well as different product ions. The CID spectrum of the $\mathrm{MH}^{+}$ion of Compound 20 is shown in Figure 6b. The neutral loss observed from the spectrum is $\mathrm{CH}_{2} \mathrm{O}$, not $\mathrm{CD}_{2} \mathrm{O}$, which shows that the proton transfers to the $\alpha$-carbon in the $4-N, N$-dimethylphenyl group and rarely to the phenyl- $d_{5}$. In light of all the above results and discussions, Scheme 2 proposes the probable fragmentation pathways.

The fragmentation pathway could also be proven by examining the substituent effects. In analogy to the first series of compounds, the two product ions, b-4 and b-6,

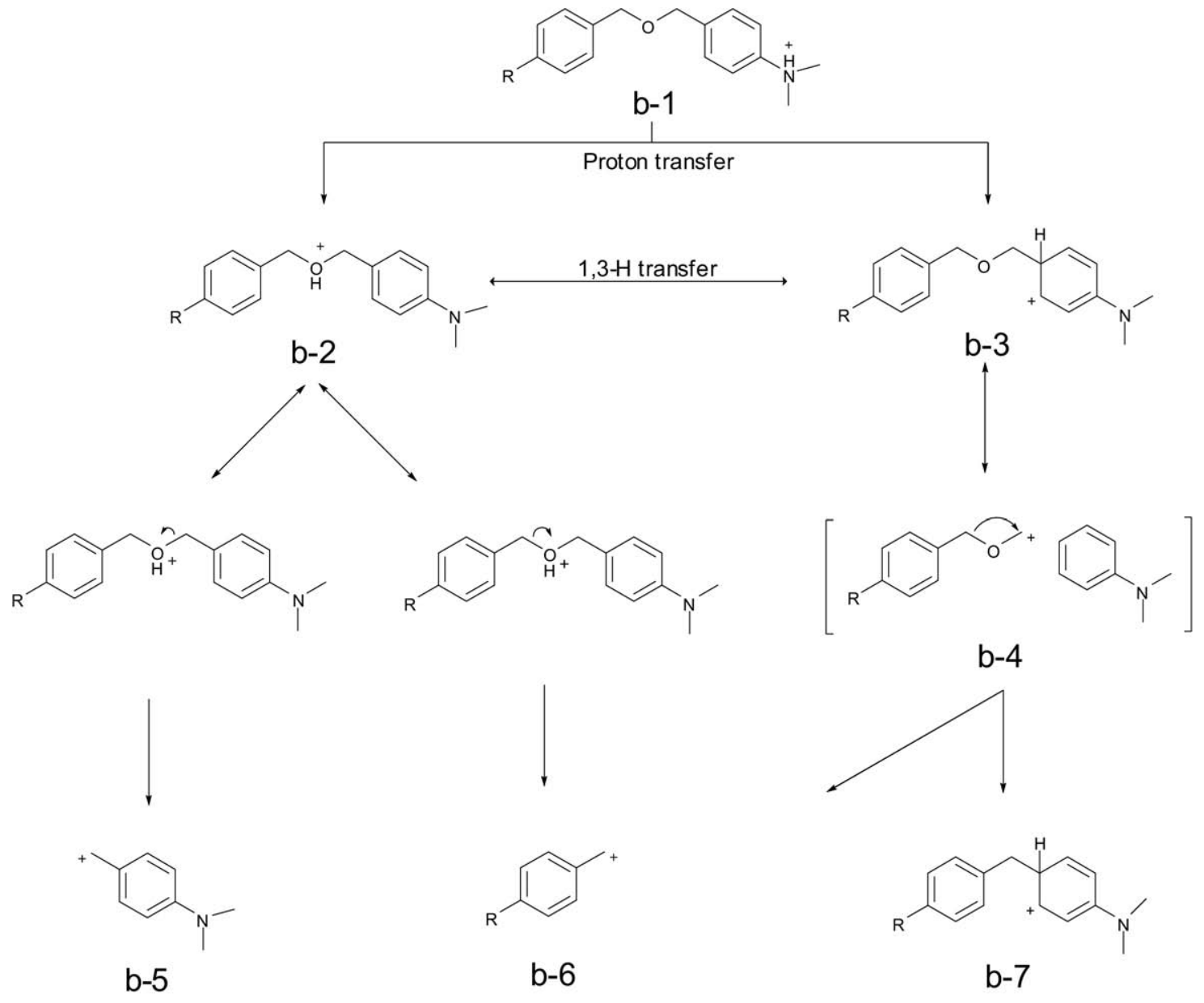

Scheme 2. Proposed MS/MS fragmentation mechanism for protonated 4-N,N-dimethylbenzyl benzyl ether and its derivatives. 


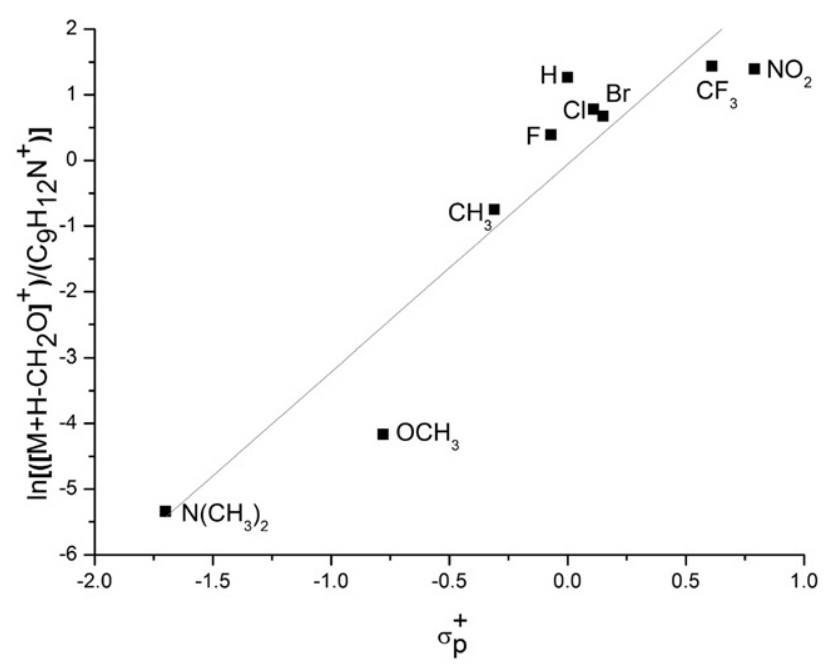

Figure 8. Plot of $\ln \left[\left(\left[\mathrm{M}+\mathrm{H}-\mathrm{CH}_{2} \mathrm{O}\right]^{+}\right) /\left(\mathrm{C}_{9} \mathrm{H}_{12} \mathrm{~N}^{+}\right)\right]$versus the $\sigma_{\mathrm{p}}{ }^{+}$substituent constants for the collision-induced fragmentation of the $\mathrm{MH}^{+}$ions of various $4-N, N$-dimethylbenzyl benzyl ethers substituted at the para position. Collision energy is $0.70 \mathrm{~V}$ (helium).

were investigated with regards to how different substituents altered their relative abundance. As with the $\alpha$-furanylmethyl $p$-substituted benzyl ethers, the variation in the intensity ratio of fragment ions b- 4 and b-6 was well-correlated with the substituent constants, $\sigma_{\mathrm{p}}^{+}$[27]. A plot of $\ln \left[\left(\left[\mathrm{M}+\mathrm{H}-\mathrm{CH}_{2} \mathrm{O}\right]^{+}\right) /\left(\mathrm{C}_{9} \mathrm{H}_{12} \mathrm{~N}^{+}\right)\right]$ versus $\sigma_{\mathrm{p}}{ }^{+}$constants gave a trend that is a reasonably good fit to a single straight line (Figure 8 ). The positive slope shows that electron-withdrawing groups, such as $\mathrm{NO}_{2}$, expedite the formation of $\left[\mathrm{M}+\mathrm{H}-\mathrm{CH}_{2} \mathrm{O}\right]^{+}$, while electron-donating groups, such as $\mathrm{NMe}_{2}$, retard its formation, which strongly supports the ion-neutral complex intermediate-involved mechanism.

\section{Conclusion}

Protonated $\alpha$-furanylmethyl benzyl ether, $4-N, N-$ dimethylbenzyl benzyl ether and their derivatives have been studied by ESI tandem mass spectrometry. The main fragmentation to give $\left[\mathrm{M}+\mathrm{H}-\mathrm{CH}_{2} \mathrm{O}\right]^{+}$can only be observed when the proton migrates from the initial protonation site to the dissociative protonation site, an aromatic ring, which forms an ion-neutral complex intermediate that loses $\mathrm{CH}_{2} \mathrm{O}$ via decomposition. This pathway was clarified by energy calculations and isotope-labeling experiments. The substituent groups on the phenyl ring may affect the fragmentation process, which was indicated by the relatively good correlations between $\ln \left[\left(\left[\mathrm{M}+\mathrm{H}-\mathrm{CH}_{2} \mathrm{O}\right]^{+}\right) /([\mathrm{M}+\mathrm{H}-\right.$ $\left.\left.\left.\mathrm{CH}_{2} \mathrm{O}-\mathrm{C}_{6} \mathrm{H}_{5} \mathrm{R}\right]^{+}\right)\right]$and the substituent constants. In addition, these two series of compounds are representative of $\alpha$-aromaticmethyl benzyl ethers in general, and of dibenzyl ether in particular. Consequently, the prevalent loss of $\mathrm{CH}_{2} \mathrm{O}$ and its mechanism, which involves an ion-neutral complex intermediate that results from dissociative protonation, is universal among $\alpha$-arometicmethyl benzyl ethers.

\section{Acknowledgments}

Y.P. thanks the National Science Foundation of China for grant 20975092, the Ministry of Education of China for grant NCET-060520, and the Natural Science Foundation of Zhejiang Province for grant Z206510.

\section{Appendix A Supplementary Material}

Supplementary material associated with this article may be found in the online version at doi:10.1016/ j.jasms.2009.12.005.

\section{References}

1. Su, T.; Bowers, M. T. Ion-Polar Molecule Collisions: The Effect of Ion Size on Ion-Polar Molecule Rate Constants; the Parameterization of the Average-Dipole-Orientation Theory. Int. J. Mass Spectrom. Ion Phys. 1973, 12, 347-356.

2. Sunner, J.; Nishizawa, K.; Kebarle, P. Ion-Solvent Molecule Interactions in the Gas Phase. The Potassium Ion and Benzene. J. Phys. Chem. 1981, $85,1814-1820$

3. Morton, T. H. Gas Phase Analogues of Solvolysis Reactions. Tetrahedron 1982, 38, 3195-3243.

4. Rylander, P. N.; Meyerson, S. Organic Ions in the Gas Phase. I. The Cationated Cyclopropane Ring. J. Am. Chem. Soc. 1956, 78, 5799-5802.

5. McAdoo, D. J. Ion-Neutral Complexes in Unimolecular Decompositions. Mass Spectrom. Rev. 1988, 7, 363-393.

6. Nibbering, N. M. M. Gas-Phase Ion/Molecule Reactions as Studied by Fourier Transform Ion Cyclotron Resonance. Acc. Chem. Res. 1990, 23, 279-285.

7. Bowen, R. D. Ion-Neutral Complexes. Acc. Chem. Res. 1991, 24, 364-371.

8. Longevialle, P. Ion-Neutral Complexes in the Unimolecular Reactivity of Organic Cations in the Gas Phase. Mass Spectrom. Rev. 1992, 11, 157-192.

9. McAdoo, D. J.; Morton, T. H. Gas-Phase Analogues of Cage Effects. Acc. Chem. Res. 1993, 26, 295-302.

10. Hudson, C. E.; McAdoo, D. J. 1,2-Eliminations from $\left(\mathrm{CH}_{3}\right)_{2} \mathrm{NH}^{+}$ $\mathrm{CH}_{2} \mathrm{CH}_{3}$ and $\left(\mathrm{CH}_{3}\right)_{2} \mathrm{NH}_{2}^{+}$: Guided Dissociations. J. Am. Soc. Mass Spectrom. 2008, 19, 1491-1499.

11. Soldi-Lose, H.; Schroeder, D.; Schwarz, H. Computational and Experimental Exploration of the Gas-Phase Chemistry of Alkyloxalate Ions ROCOCOO $^{-}\left(\mathrm{R}=\mathrm{H}, \mathrm{CH}_{3}, \mathrm{C}_{2} \mathrm{H}_{5}, i-\mathrm{C}_{3} \mathrm{H}_{7}\right.$, and $\left.t-\mathrm{C}_{4} \mathrm{H}_{9}\right)$. Int. J. Mass Spectrom. 2008, 269, 62-70.

12. Dechamps, N.; Flammang, R.; Gerbaux, P.; Nam, P.; Nguyen, M. Decarboxylation of Metastable Methyl Benzoate Molecular Ions. J. Am. Soc. Mass Spectrom. 2006, 17, 807-814.

13. Attygalle, A. B.; Bialecki, J. B.; Nishshanka, U.; Weisbecker, C. S.; Ruzicka, J. Loss of Benzene to Generate an Enolate Anion by a Site-Specific Double-Hydrogen Transfer During CID Fragmentation of $o$-alkyl ethers of ortho-hydroxybenzoic acids. J. Mass Spectrom. 2008, 43, 1224-1234.

14. van Beelen, E. S. E.; Molenaar-Langeveld, T. A.; Ingemann, S. A Chemical Ionization Study of Deuteron Transfer Initiated Propene Loss from Propoxypyridines. J. Am. Soc. Mass Spectrom. 2003, 14, 1166-1176.

15. Julian, R. R.; Ly, T.; Finaldi, A.; Morton, T. H. Dissociation of a Protonated Secondary Amine in the Gas Phase Via an Ion-Neutral Complex. Int. J. Mass Spectrom. 2007, 265, 302-307.

16. Matthias, C.; Cartoni, A.; Kuck, D. Ion-Neutral Complexes Generated During Unimolecular Fragmentation: Intra-Complex Hydride Abstraction by tert-Butyl Cations from Electron-Rich and Electron-Poor 1,3Diphenylpropanes. Int. J. Mass Spectrom. 2006, 255/256, 195-212.

17. Hammerum, S.; Jensen, L. B.; Mohr, M. Isotope Effects on the Unimolecular Dissociation of Ionized 3-Methyl-2-butanol: Reactions via a Long-Lived C-H-C Hydrogen-Bridged Ion-Neutral Complex. J. Phys. Chem. A 2005, 109, 3159-3165.

18. Tu, Y. P. Fragmentation of Conjugated Amides at the $\mathrm{C}-\mathrm{C}(\mathrm{O})$ Bond in Electrospray Mass Spectrometry: A Proton-Bound Dimeric Intermediate Identified by the Kinetic Method. Rapid Commun. Mass Spectrom. 2004, 18, 1345-1351.

19. Tu, Y. P. Dissociative Protonation Sites: Reactive Centers in Protonated Molecules Leading to Fragmentation in Mass Spectrometry. J. Org. Chem. 2006, 71, 5482-5488.

20. Berruyer-Penaud, F.; Bouchoux, G.; Payen, O.; Sablier, M. Structure, Reactivity, and Thermochemical Properties of Protonated Lactic Acid. J. Mass Spectrom. 2004, 39, 613-620. 
21. Denekamp, C.; Stanger, A. Substituent Effect and Multisite Protonation in the Fragmentation of Alkyl Benzoates. J. Mass Spectrom. 2002, 37, 336-342.

22. Kingston, E. E.; Shannon, J. S.; Diakiw, V.; Lacey, M. J. Skeletal Rearrangements on Chemical Ionization of Dibenzyl Ether and Derivatives. Org. Mass Spectrom. 1981, 16, 428-440.

23. Hu, N.; Tu, Y. P.; Liu, Y.; Jiang, K.; Pan, Y. Dissociative Protonation and Proton Transfers: Fragmentation of $\alpha, \beta$-Unsaturated Aromatic Ketones in Mass Spectrometry. J. Org. Chem. 2008, 73, 3369-3376.

24. Tu, Y. P.; Huang, Y.; Atsriku, C.; You, Y.; Cunniff, J. Intramolecular Transacylation: Fragmentation of Protonated Molecules Via Ion-Neutral Complexes in Mass Spectrometry. Rapid Commun. Mass Spectrom. 2009, 23, 1970-1976.
25. Hunter E. P. L.; Lias, S. G. Evaluated Gas Phase Basicities and Proton Affinities of Molecules: An Update. J. Phys. Chem. Ref. Data 1998, 27 413-656.

26. Lorenz, U. J.; Lemaire, J.; Maitre, P.; Crestoni, M. E.; Fornarini, S.; Dopfer, O. Protonation of Heterocyclic Aromatic Molecules: IR Signature of the Protonation Site of Furan and Pyrrole. Int. J. Mass Spectrom. 2007, 267, 43-53.

27. Hansch, C.; Leo, A.; Taft, R. W. A Survey of Hammett Substituent Constant and Resonance and Field Parameters. Chem. Rev. 1991, 91, 165-195.

28. Thielking, G.; Filges, U.; Griitzmacher, H.-Fr. Remote Fragmentations of Protonated Aromatic Carbonyl Compounds Via Internal Reactions in Intermediary Ion-Neutral Complexes. J. Am. Soc. Mass Spectrom. 1992, 3 , 417-426. 